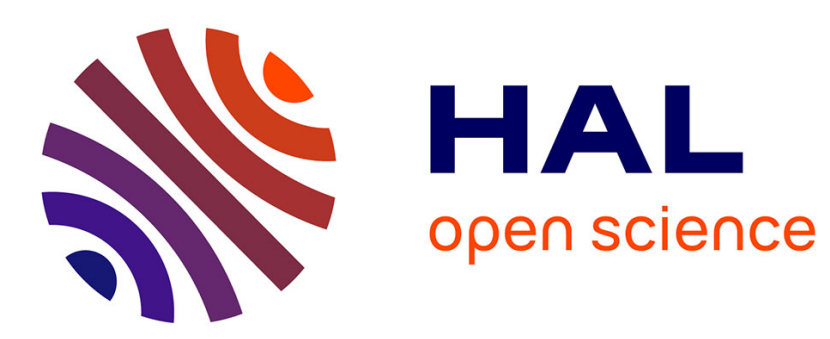

\title{
Catenary-based nonlinear multimodal theory of cable free vibrations
}

\author{
Achref Mansour, Giuseppe Rega
}

\section{To cite this version:}

Achref Mansour, Giuseppe Rega. Catenary-based nonlinear multimodal theory of cable free vibrations. NODYCON 2019, Feb 2019, Rome, Italy. hal-01965944

\section{HAL Id: hal-01965944 \\ https://hal.science/hal-01965944}

Submitted on 27 Dec 2018

HAL is a multi-disciplinary open access archive for the deposit and dissemination of scientific research documents, whether they are published or not. The documents may come from teaching and research institutions in France or abroad, or from public or private research centers.
L'archive ouverte pluridisciplinaire HAL, est destinée au dépôt et à la diffusion de documents scientifiques de niveau recherche, publiés ou non, émanant des établissements d'enseignement et de recherche français ou étrangers, des laboratoires publics ou privés. 


\title{
Catenary-based nonlinear multimodal theory of cable free vibrations
}

\author{
Achref Mansour*, Giuseppe Rega* \\ *Université de Tunis El Manar, Ecole Nationale d'Ingénieurs de Tunis, LGC, BP 37, Le Belvédère, 1002, Tunis, Tunisia \\ ** Dipartimento di Ingegneria Strutturale e Geotecnica, Università di Roma La Sapienza, Via A. Gramsci 53, 00197 Roma, \\ Italy
}

\begin{abstract}
Keeping the linear elastic material assumption and accounting for the sole axial extensibility, a new multi-modal theory of cable nonlinear free vibrations is developed analytically, by means of a Galerkin discretization of partial differential equations of motion and the Method of Multiple Scales used to investigate the dynamic behaviour of arbitrarily sagged and inclined cables oscillating around a catenary static profile.
\end{abstract}

\section{Introduction}

Accounting for their wide use in a variety of engineering applications and owing to their theoretical interest, cable vibrations have been the subject of numerous studies from the late 1970's [1] until now. Linear and nonlinear dynamics have been discussed according to different assumptions related to the cable geometrical and mechanical characteristics. Seminal works dedicated to the study of highly pre-stressed and small sagged cables have been analytically performed considering a linear expression of the dynamic deformation defined with respect to a parabolic/cubic static profile due to the linearisation of the real catenary geometry $[2,3]$. In such situation, cable vibrations were found to be fully described by classical normal modes. However, given the weak geometrical nonlinearity of the linearised static equilibrium position, linear cable dynamics exhibit special regions where the orthogonality condition is violated due to commensurability relationships between vibration frequencies known as 1:1, 2:1 and 3:1 internal resonances. On the other hand, the aforementioned models are also based on the so-called "kinematic condensation" where longitudinal inertia and dynamic deformation are neglected leading to the reduction of the in-plane dynamics to its transverse component. These researches have been complemented by various models discussing cable nonlinear oscillations $[4,5]$ as well as analytical frameworks investigating the role as well as the activation conditions of internal resonances and coupled nonlinear normal modes [6,7]. Yet, a detailed review of the literature found in [8] demonstrates that the previous considerations are still assumed by the majority of the existing models, even those developed for loose cables where the influence of large displacements becomes increasingly important. In fact, few efforts have been devoted to the oscillations of non-shallow cables where the catenary geometry has been adopted to define the static reference configuration $[9,10]$. Recently, the linear modal properties of arbitrarily sagged and inclined cables have been investigated in the light of a catenary-based model developed analytically by Mansour et al. [11]. Taking into account the induced geometric nonlinearity effect, new modal spectrum characterized by higher ratios of internal resonances has been highlighted where non-normal modes are continuously detected. Nevertheless, the condensation assumption as well as the linearisation of cable dynamics remain the major assumptions limiting the validity range of the proposed solution. Furthermore, it is very interesting to study the activation conditions of the newly highlighted internal resonances and their effect on the coupling between non-normal modes since they exhibit a variety of extremely rich phenomena caused by the structural low rigidity and negligible damping characteristics. Accordingly, the present work is pursued in sequence with these recently obtained results. As a matter of fact, a catenary-based theory is developed analytically using the Method of Multiple Scales (MMS) [12] in order to solve the dynamic problem in its original nonlinear form. The proposed solution will take into consideration the geometric nonlinearities induced by the multimodal quadratic and cubic couplings between the dynamic displacement components as well as the influence of the condensation assumption. Once the analytical solution is formulated, the stability conditions of the obtained non-normal displacements as well as the activation conditions of the internal resonances are derived. Finally, numerical investigation of both additional dynamic displacements and cable final tension is performed. A comparison with the results obtained by existing models is also accomplished in order to highlight the main differences caused from one side by the linearisation of the initial catenary profile, and from the other side by the condensed kinematics considered in the literature $[4,5]$.

\section{Multiple scale solution}

In the present analysis, the attention is held on the dynamic properties of a homogeneous linearly elastic cable hanged between two fixed supports and characterized by a non deformable cross-section. A modal decomposition is first used to express the longitudinal, transversal and out-of plane dynamic displacements denoted respectively by $u_{1}, u_{2}$ and $u_{3}$ and defined in the strained arclength coordinate $s$ as follows:

$$
u_{i}(s, t)=\sum_{k=1}^{N} \varphi_{k, i}(s) q_{k, i}(t) \quad \forall i \in\{1,2,3\}
$$


where $\varphi_{k, i}$ and $q_{k, i}$ denote respectively the modal shape and the time coordinate of the $k^{t h}$ mode in the $i^{t h}$ direction.

At this stage, it should be noted that the longitudinal displacement is assumed as totally independent of the transversal one, thus developing a non-condensed model whose in-plane longitudinal/transversal modal properties are disjoint in both the spatial and the frequency domain. Accordingly, the eigenvalue problem defined with respect to the catenary curved configuration is first solved for non-condensed kinematics leading to accurate expressions of both modal shapes and vibration frequencies. Substituting the obtained eigenfunctions and eigenvalues in the nonlinear dynamic problem yields a new time-dependent differential system solved by virtue of a semi-analytical procedure based mainly on the MMS. A compact form of the analytical solution may be expressed as below:

$$
u_{i}(s, t)=\sum_{j=1}^{3} \sum_{k=1}^{N} C_{k, i}(\Lambda, \Gamma, a) \varphi_{k, j}(s) \cos \left[\sum_{j=1}^{3} \sum_{k=1}^{N} \Omega_{k, j} t+\psi_{k, j}\right]
$$

where $C_{k, i}$ are correction functions depending on quadratic and cubic nonlinearity coefficients $\Lambda$ and $\Gamma$ from one side and on the amplitudes $a$ on the other side, $\Omega$ are the nonlinear frequencies and $\psi$ the relative phases. The proposed solution has the advantage to account for both catenary-induced geometric nonlinearity as well as quadratic and cubic nonlinearities associated with the modal coupling between additional dynamic displacements in its largest sense. Consequenlty, not only additional dynamic tension is reviewed in the light of the newly formulated theory but the internal resonances described by existing models are also investigated. In view of an extremely rich scenario of possible nonlinear modal interactions ensuing from the catenary-based formulation and enhanced by the non-condensation assumption, the amplitude and phase modulation equations are derived analytically in the case of M:1 internal resonance, and the associated stability features are analysed. The accuracy of the proposed results is tested with reference to analytical expressions available in the literature for some cases of 2:1 and 3:1 internal resonance [6].

\section{Conclusions}

In the framework of a catenary-based formulation, features of modal interaction and cable total tension of the present model (formulated in the strained arclength coordinate and fully non-condensed) are numerically investigated against the results exhibited by either a non-condensed model or a solely spatially non-condensed finite difference model formulated in the chordwise coordinate $[4,5]$. With respect to non-condensed models, condensation entails an underestimation of the cable maximum tension (a quantity of considerable importance from the engineering viewpoint) which is as larger as the former is formulated in the arclength coordinate and accounts for both spatial and frequency modal independence of longitudinal and transversal displacements. The new multi-modal asymptotic theory may be considered as a powerful tool to accurately determine the cable dynamic responses in terms of additional displacements and tension. In a wider perspective, it also offers a systematic framework to determine the activation conditions of M:1 internal resonances and the associated stability regions.

\section{References}

[1] Irvine H. M. (1981) Cable Structures. The MIT Press, Cambridge.

[2] Triantafyllou M.S. (1984) The dynamics of taut inclined cables. Q J Mechanics Appl Math 37(3):421-440.

[3] Zhou, X., Yan, S., Chu, F. (2011) The in-plane free vibrations of an inclined taut cable. Journal of Vibration and Acoustics 133 (3): Paper No. 031001, pp. 1-9.

[4] Srinil, N., Rega, G., and Chucheepsakul, S. (2003) Large amplitude three-dimensional free vibrations of inclined sagged elastic cables. Nonlinear Dynamics 33: 129-154.

[5] Srinil, N., Rega, G., and Chucheepsakul, S. (2004) Three-dimensional non-linear coupling and dynamic tension in the large-amplitude free vibrations of arbitrarily sagged cables. Journal of Sound and Vibration 26(3):823-852.

[6] Lacarbonara, W., Rega, G., Nayfeh, A.H. (2003) Resonant non-linear normal modes. Part I: Analytical treatment for structural onedimensional systems. International Journal of Non-Linear Mechanics 38(6):851-872.

[7] Lacarbonara, W., Rega, G. (2003) Resonant non-linear normal modes. Part II: Activation/orthogonality conditions for shallow structural systems. International Journal of Non-Linear Mechanics 38(6):873-887.

[8] Rega, G. (2011) Theoretical and experimental nonlinear vibrations of sagged elastic cables. Nonlinear Dynamic Phenomena in Mechanics (Eds. J. Warminski et al.)157-207. Springer.

[9] Lacarbonara, W., Paolone, A., Vestroni, F. (2007) Elastodynamics of nonshallow suspended cables: linear modal properties. Journal of Vibration and Acoustics 129(4):425-433.

[10] Lacarbonara, W., Paolone, A., Vestroni, F. (2007) Non-linear modal properties of non-shallow cables. International Journal of NonLinear Mechanics 42(3):542-554.

[11] Mansour, A., Ben Mekki, O., Montassar, S., Rega, G. (2018) Catenary-induced geometric nonlinearity effects on cable linear vibrations. Journal of Sound and Vibration 413:332-353.

[12] Nayfeh A.H. (2008) Perturbation Methods (First edition 1973). John Wiley and Sons. 